\title{
Smart Parking Guidance System Using 360o Camera and Haar-Cascade Classifier on IoT System
}

\author{
Salma, Rashidah Funke Olanrewaju, Morshidi Malik Arman
}

\begin{abstract}
Nowadays, smart parking guidance system is a crucial research for people's convenience. The main objective of this research is to develop and analyze on a smart parking guidance system where current available system was compared to this new proposed system. Limited parking space has become serious issue since the number of Malaysia's populations who are using car keep increasing. Some of the big companies, shopping malls and other public facilities already deployed a smart parking system on their building. However, there are still a lot of buildings that do not own it because the system required a lot of investment, where the huge parking areas need higher cost to install sensors on each parking lot available. The proposed smart parking guidance system in this research was depending on a $360^{\circ}$ camera that was modified on raspberry pi camera module and $360 \mathrm{o}$ lens and Haar-Cascade classifier. The image and video processing was by Open $C V$ and python program to detect the available parking space and cloud firebase was used to update data where users can access the parking space availability by android mobile phone specifically at a closed parking space. A single $360^{\circ}$ camera was replaced several sensors and camera which was implemented on traditional smart parking system. An analysis was done on the performance of the system where it can detect the parking availability with $99.74 \%$ accuracy and which is far better than conventional system including reliability and cost for the parking space guidance system.
\end{abstract}

Keywords - Internet of Things; Cloud Computing;Raspberry Pi 3 model B, 360-degree camera, Smart Parking; Android app. .

\section{INTRODUCTION}

A lot of study and researches have been conducted regarding smart parking system that already implemented around the globe such as (Prasse \& Nettstraeter, 2014).Most of the research have proposed an upgrade and improvement to the conventional system according to the situation of the parking space that vary everywhere. The increasing number of researches on smart parking system have conducted until now telling us that the communities and industries still demand for a better system. Numerous smart parking system have today that are mostly using sensors to detect parking lots availability which is costly and lower in accuracy and reliability offered by the system. Some of the smart parking system that already available for installation nowadays. Both

Revised Version Manuscript Received on 16 September, 2019.

Salma, Electrical and Computer Engineering, International Islamic University Kuala-Lumpur, Malaysia.

(Email: mirsalma12@yahoo.com)

Rashidah Funke Olanrewaju, Electrical and Computer Engineering, International Islamic University Kuala-Lumpur, Malaysia.

(Email: frashidah@iium.edu.my)

Morshidi Malik Arman, Electrical and Computer Engineering, International Islamic University Kuala-Lumpur, Malaysia.
(Email: mmalik@iium.edu.my)

systems, either magnetic sensor or ultrasonic sensor are not very effective in term of cost. It is because both systems are requiring to install the sensors on every parking lot. So, it might be costly to implement. Thus, an improvement is made in this research in term of accuracy and implementation cost and reliability of the system.

\section{THE $360^{\circ}$ SMART PARKING GUIDANCE SYSTEM}

The $360^{\circ}$ Smart Parking Guidance System is a complex integration between Internet of Things (IoT) concept and image or video processing technology which made up a complete smart parking system. This research consisted of several parts such as camera technology, cloud system and end user application. The focus is on the development of $360^{\circ}$ camera technology as the sensor and raspberry pi 3 model B was integrated with an image processing, mobile application and cloud system as what stated in the objective. For a simulation purposes, 5megapixel camera was used, and it is modified to become a $360^{\circ}$ view camera by attaching additional lenses. Any image or video capturing processed through a python program and Open CV libraries before the data live on Firebase cloud platform and end user application. All of these was a concept of IoT architecture as depicted in the figure 1 .

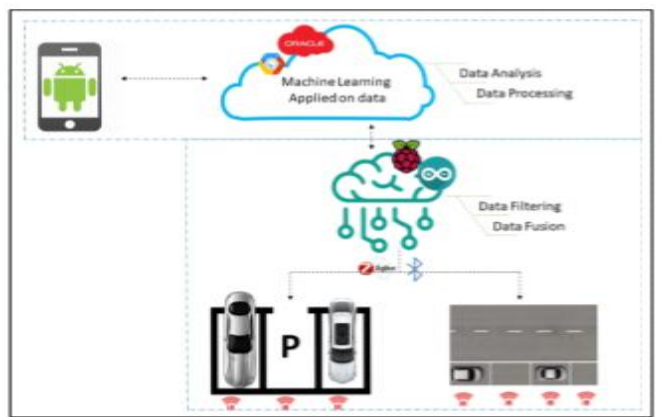

Figure 1. IoT architecture concept(Alsafery \& Reiff-marganiec, 2018)

\section{INTERNET OF THINGS (IoT)}

The system of IoT is interconnected with computing devices, mechanical and digital machines, objects, animals and humans. It has the capability of transferring information from one device to another device without the help of any human resources. Internet of Things(IoT) first expressed by Kevin aston who is the executive director of Auto-ID

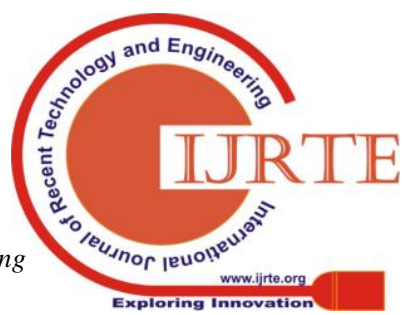


Center.Today the IoT market scope is reaching at new levels that is estimated by the report of Gartnera in 2011 (Sardeshmukh \& Ambawade, 2018).The IoT is highly flexible and feasible in efficiency that is highly depends on the algorithm which correlating and analysing the collected data through the quality of image data of IoT(Benita \& Chalissery, 2017). Machine Vision is the promising solution to improve the current solution of IoT smart parking guidance system. This system consists of IoT, mobile application together with machine vision through digital image processing. Cloud Firebase is used as the database to store data collected from $\mathrm{Pi}$ at the same time allows mobile app, On the other hand, Firebase is used to enable user login and communication platform data storage. All users are need to register to the application with their user name, email and car-plate number. Besides, with the mobile application, drivers can reserve the parking space in advance. This system reduces the time for drivers to find and reserve the parking space

\section{CLOUD COMPUTING WITH IOT}

Internet of Things(IoT) and cloud computing are two very different technologies. Cloud computing involves to deliver data, application, videos, image through the internet to data centers. Meanwhile, the Internet of Things refers internet connection of devices. All services, storage, data sharing and other system resources are available in the cloud for public use. The sharing process of all these data is called cloud computing and it is highly interrelated with the concept of IoT. By referring to(Hall, 2010), cloud computing architecture is always free and shareable with the world communities. It is important to keep it open-source because the system can be easily improved by the communities it self. "Cloud computing is categorized under three sub-group which is Public Cloud - available to all, Private Cloud within an organization and Hybrid Cloud, which combined both cloud architecture model. The storage service available in the cloud is very huge and it is capable of handling real time activities and notifications required by lot of IoT devices (Princy \& Nigel, 2015).Due to the existence of cloud computing some industrial equipment is replaced by a Cloud Robotics who can help in the automation process.(V, 2016) Human workforce can be reduced while the efficiency of the works increased due to data sharing available in the cloud storage(V, 2016). Raspberry pi board encompasses System on a Chip (SoC) it means it is a method of grouping all the valuable electronics to run on the individual chip and it also uses processor Broad com BCM2837 for various interfaces. Raspberry pi is flexible; it can use for general purpose computing. Hence, it is used for smart parking guidance system in this research while another solution was proposed by (Maenhaut, Volckaert, Ongenae, \& Turck, 2017) with the title, Demo Abstract: RPiaaS: A Raspberry Pi Testbed for Validation of Cloud Resources Management Strategies. "The test-bed provides an easy-to-use environment for the initial evaluation of novel cloud resource management strategies and is designed to facilitate the step from simulations towards experimental evaluations on larger cloud tested.(Maenhaut et al., 2017). (Durnyak \& Havrysh, 2018) computer vision techniques involved Fourier transform to process the input signal from a picture or video.

\section{RASPBERRY Pi WITH IoT}

Raspberry $\mathrm{Pi}$ is a small computer that is widely used by the inventors, engineers and hobbyists to create an interesting research especially related to IoT research that needs connection to the cloud. Nowadays, Raspberry Pi becomes the most favourite processor to implement into a research because it is cheap and open source. A lot of information, tutorials, specifications and other miscellaneous data are freely available on the internet itself. Those data are important for an improvement to be made in the future. It is reliable for the commercial purposes as we can see several researches have been conducted by using Raspberry Pi either as the main component or supported component. In research paper(Collage, Collage, \& Collage, 2017) and (Ojrulwkp et al., 2017) Raspberry Pi was implemented into a smart parking system. The author said that the objective of the research achieved while they managed to minimize the cost(Collage et al., 2017). On the other hand, (Korea, 2016)shows that Raspberry Pi can be used as a support component in a Smart Home system implemented developer version of Raspberry Pi 2 into their predictive Smart Home application and act as terminal system which able to communicate with the cloud server effectively. Figure 2 shows the architecture of the system for . Other than that, Raspberry Pi has been used to power cloud server in (Aktaruzzaman, Badhan, Adnan, \& Alam, 2017) Smart Sensor Network for Smart Buildings(Lobachev, 2016), water Quality Monitoring system (Engineering, 2015)and a low-cost video trans-coder (Barais, Bourcier, \& Dion, 2016). Smart Car Parking Management System Using IoT is a research where proposed method had developed the traditional servicing channels like parking attendance and toll-both. They used Arduino Uno, Ultrasonic sensor, cloud server and Wi-Fi Module where the Internet of Things integrate software, hardware and network connectivity which allows to sense object and control remotely. However, the Arduino Uno has no any own operating system like Raspberry Pi.It needs to use windows or Mac OS. Thus while it will use any additional feature like Ethernet connection, video streaming and Bluetooth connection etc.- it may increase extra cost more than itself because of requiring to buy extra shields. Hence, Raspberry pi is selected for this research based on its feature and price.

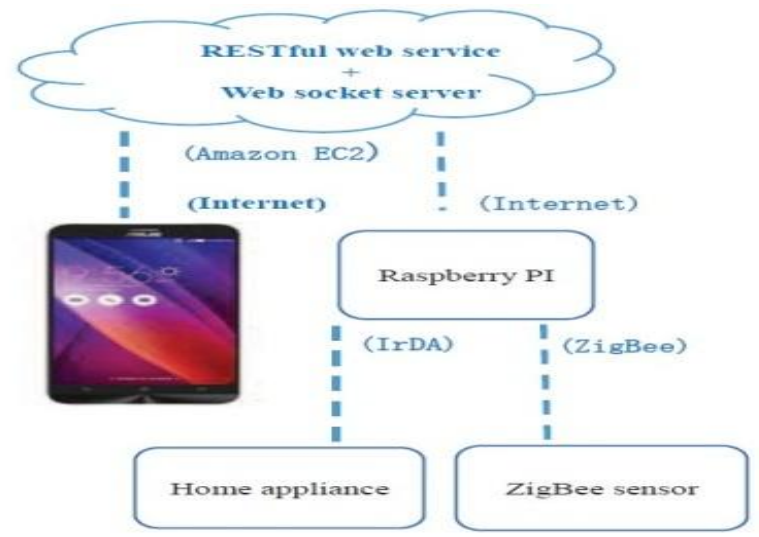

Figure 2. Raspberry Pi implemented in Smart Home system(Korea, 2016) 
First part introduces the research area and overview of the research. A comprehensive review of the literature on this research area represents in part two. We reviewed different smart parking guidance techniques that apply for finding available parking space for this research purposes. Third part describe the methodology used in this research and fourth, fifth and sixth and the rest part introduces the result, the user acceptance test for the system, discussion, conclusion and future work simultaneously.

\section{RELATED WORK}

Past few years, smart parking system have been demanded by the communities across the globe and it can be seen in almost every developed country nowadays. Tremendous amount of research on smart parking system been conducted every year. Since then, this kind of high technology system has gone through big improvement. It all started with wired sensors being used and installed on every available parking slots just to detect the presence of a vehicles.(Kumar, Chilamkurti, \& Soh, 2007) did mention in their paper, one of the famous research being conducted during that time is Siemens Si Park. After that, people started to realize that the old system need an improvement on detection accuracy, reliability, installation cost power consumption, communication protocols, communication efficiency, and time used to find parking lot, signals delay and much more. There are many researcher for example (Guerrero-Ibáñez, Zeadally,\& Contreras-Castillo, 2018)used sensor technology for detecting the parking system where sensor based parking guidance system is designed for indoor parking. This system is harder to be implemented as it need wirings to interconnect sensors and LED. (Ng, Loong, Isaak, \& Yusof, 2019) proposed vision based smart parking system using Internet of Things where 5megapixel camera is used that was connected to Raspberry pi 3 model B camera module and canny edge detection technique was used as method for detection. Image quality is improved and detecting the parking vacancy with $98 \%$ accurately in real time. However, the accuracy of this method may improve by using better camera and method. (Bibi, Majid, Dawood, \& Guo, 2017) have done a research on

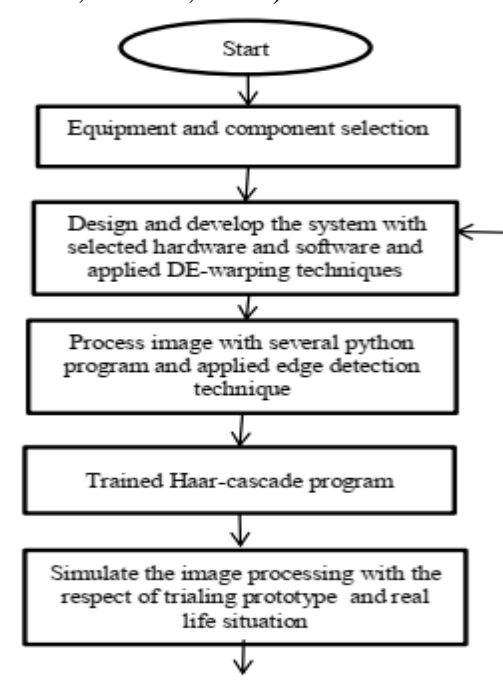

Figure:3. Smart parking guidance system
Automatic Parking Space Detection System. A web camera is used to get the images of the parking area and image processing techniques are used to detect the presence or absence of cars to count and locate the available parking spaces which achieved the average performance is $99.5 \%$ and is very high as compared with other parking lot detections applications. The result shows that when the captured images of the parking lot are not clear because of less lighting or occlusions, the efficiency decreases and the accuracy for detection's reduces. (Bao, Zhan, $\mathrm{Xu}, \& \mathrm{Hu}$, 2017) have work on A novel dual microwave Doppler Radar based vehicle detection sensor for parking IoT occupancy detection. Doppler radar transceiver module was used to detect the movement of a parking vehicle where motion recognition method was presented to identify the vehicle behavior and generate the parking space occupancy Doppler radar sensor detected the vehicle movement clearly and the detection accuracy achieved higher than $98 \%$. However, the system design is more complicated.(Dokur, Katkoori, \& Elmehraz, 2016) have developed Embedded System Design of a Real-time Parking Guidance System. This system consists of Arduino, ultrasonic sensor, and a temperature sensor. Detection logic was then developed to identify a car after analyzing the initial test results. This logic was extended to trigger a camera to take an image of the vehicle for validation purposes. The proposed system has mitigated their objective. However, ultrasonic sensor is expensive in installation because it requires a sensor for each park and its sensitivity to the fluctuation of temperature and extreme air turbulence.

\section{REARCH METHODOLOGY}

The research purpose was to explore and study the different techniques that used in smart parking guidance system to develop a cost effective process to find available parking slot and reservation purposes. The method employed in conducting this study was a simulation to achieve the research objectives. Therefore, it was briefly described about some of hardware and software system that used in this research to develop the prototype. 
SYSTEM DESIGN DEVELOPMENT WITH HARDWARE AND SOFTWARE

The system design and development of this research involved 3 stages which is image processing, cloud development and mobile application development. The main focus was on image processing as the main sensor of this research is the camera itself and it is used to detect the availability of the parking lots. In this research used Raspberry pi instead of other microprocessor for prototyping purposes mainly because of the pricesand the capability of the devices. Figure 4. below shows the whole process involved in this research. First, the Raspberry pi camera is attached to the Kogeto Dots $360^{\circ}$ lens converter. The camera is attached to the Raspberry pi port. Image processing are integrated through the Raspberry pi by using Python and Open CV. To do the simulation, the camera is placed somewhere at the center of the parking space which can get more view of the parking lots. After that, video is processed through the Raspberry pi by using a technique called edge detection which detect the changes on the pixels. The presence of a car is monitored before it is sending to the cloud (Firebase) and the user mobile application. On a user site, they can reserve any available parking space and google maps API is used to allocate the time before user arrived on the parking spot.

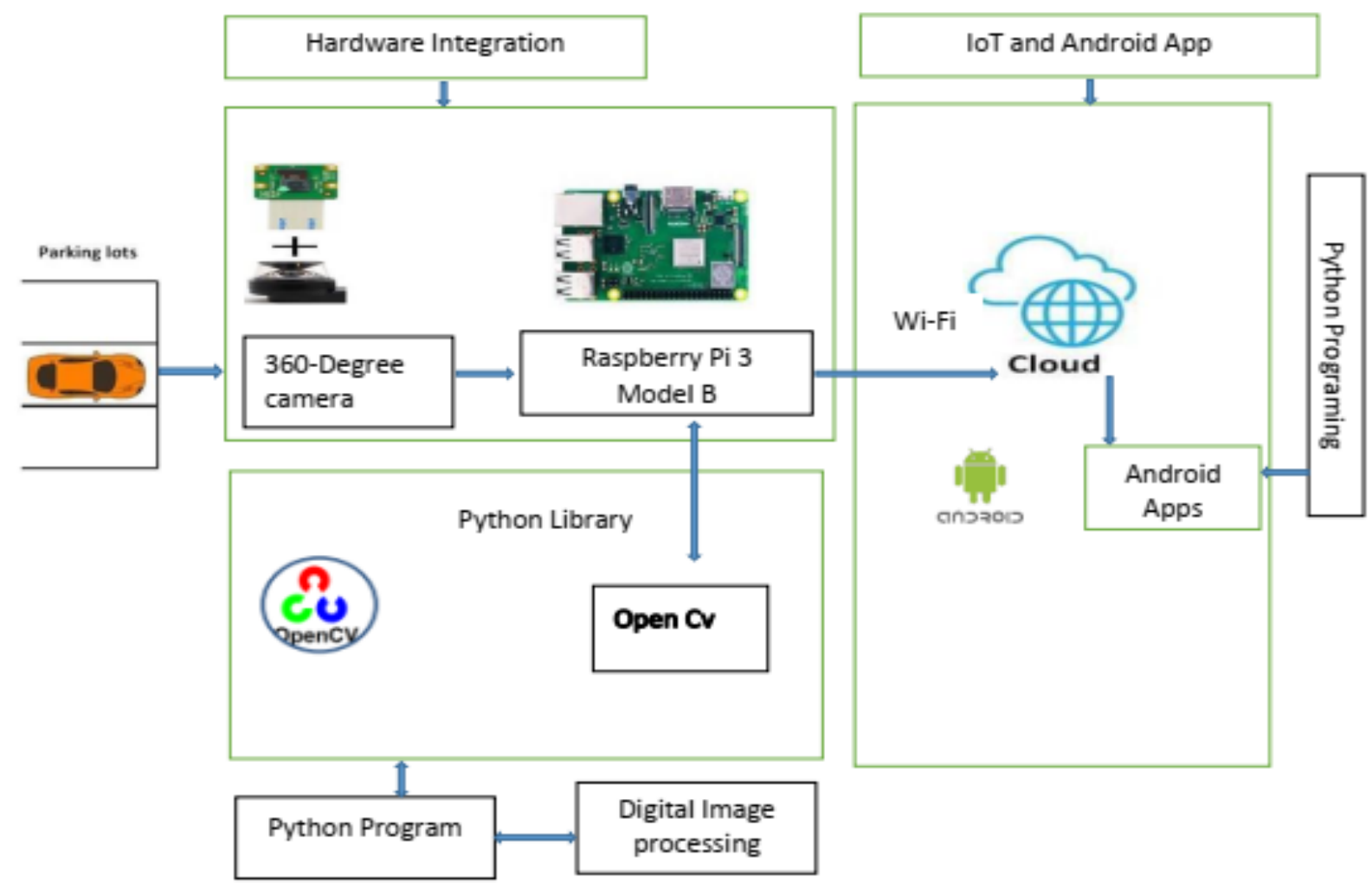

Figure.4. whole process of Smart parking guidance system method.

\section{IMAGE PROCESSING}

There is several preprocessing with python programs implemented for the image/video processing in this research such as:

- Varying the brightness of the subject

- Scaling the objects

- Blurring and sharpening the image captured

- Thresholding

- Edge detection

Edge detection is the main techniques that was used in this research. Each parking space have line edges that separated each lot. So, those lines used as background reference to specified parking space number.

\section{HAAR-CASCADE CLASSIFIER}

In the figure, shows the block diagram of the proposed method. The system tries to find the presence of the car in the parking from the video which was taken by 360-degree camera. The car image was taken from the front and back of the cars for training. The XML file was used for detecting the presence of the that was created after training the classifier. To train the program these are the main steps was taken:



Figure.5. Haar cascade training method

Published By: 
Haar Cascade is a classifier is created by the author(Viola $\&$ Jones, 2005) to detect and track the object in the image. To train the classifier positive image contain the wanted object where negative contain the unwanted object. the classifier scans the features (shown in Figure6) which create the specific target values on the positive images by using the sum values of black and the white areas of the features. For detecting and tracking the object, classifier tries to create most optimized target values by changing the size of the features. Features are the weak classifier because they can't be a correct classifier alone. The image of the object contains many feature and object where they are collected. In the image facilitate the detection of the object using a lot of positive and negative images. Classifier runs basically mentioned in the above. The efficiency of finding the object in the image depends on the method of training classifier using number of positive and negative images.

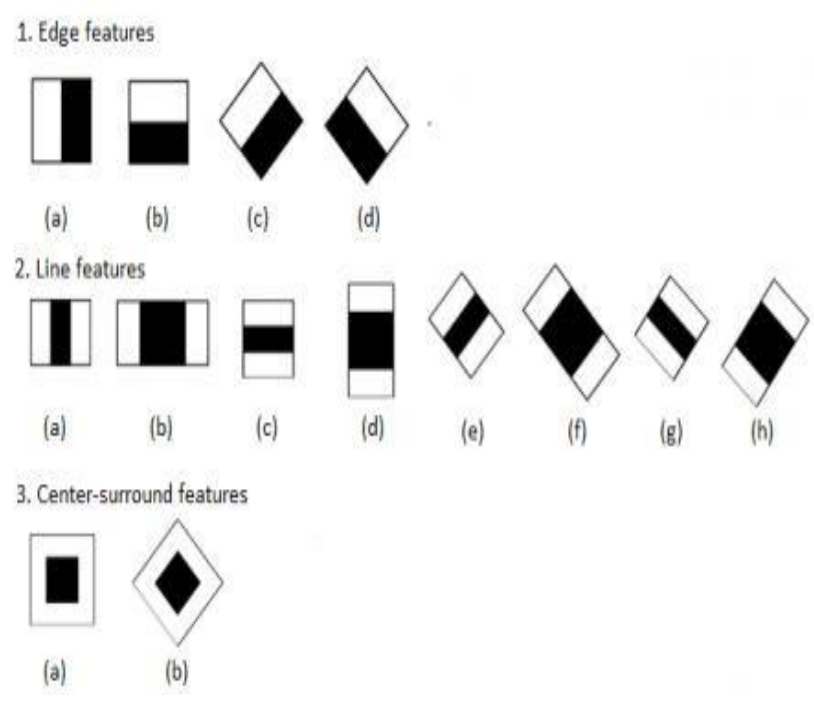

Figure:6. Features of the classifier

Haar cascade file was used together with the Open CV to be the reference on subject image. There are several precautions was followed to obtain good result such as:

- Negative images collected between 1000 to 1500 snapshot

- Negative images size was must be larger than the positive image (negative: 100x100 \& positive image: 50x50)

- The ratio of negative to positive images was $2: 1$

\section{TRAINING THE HAAR-CASCADE CLASSIFIER}

For training the classifier used lots of positive and negative images. Some positive images are shown in Figure. 8 and 9 which are taken from the source. We trained the classifier using the positive images

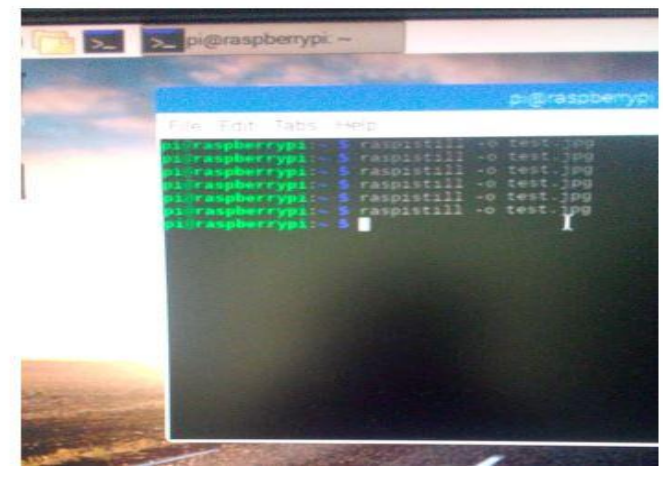

Figure:7. code for image collection.

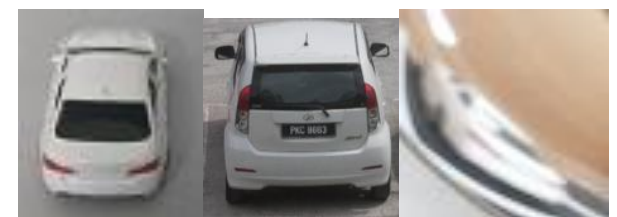

Figure 8. Positive image collected

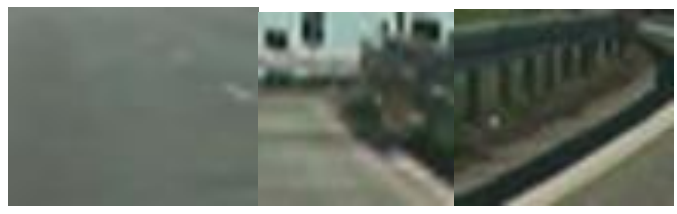

Figure 9. Negative image collected

The positive images contain the wanted object(car) but negative image does not contain the wanted object.The positive images were re-sized to $50 * 50$ pixels where negative images were re-sized to $100 * 100$ pixel and converted to vector file. After them, the number of positive images is determined that was used in training. For determining this number (x) Equation (1) is used.

$$
X \leq \frac{(\text { Number of pos.Img }- \text { Number of neg.Img })}{1+(\text { Number of stages }-1) \times(1-\text { MinHitRate })}
$$

In this equation, number, of stages indicates that in how many stages the classifier reaches to the result and the min hit Rate indicates the minimum hit rate in every stage. Other parameters to train the images are Max False Alarm Rate. First of them represents the acceptable maximum false alarm rate for the training section of object. The second one represents the memory that allocated for training the classifier. For this study, the parameters are selected as number of Stages:24, min hit Rate: 0.995, max False Alarm Rate:0.25.

\section{MOBILE APPLICATION WITH OPEN CV AND CLOUD}

This research was integrated with the mobile application in IoT. The app was created by Android studio which is integrated development environment (IDE) for the device run by Android operating system(os.) This IDE is substituted with other prominent IDE (like Eclipse, NetBeans etc.) 
because of its elasticity to the designer along with its emulator to experiment the APPs in the various devices virtually. However, the open $\mathrm{CV}$ for the image processing with Android library functions mainly intended for the real-time computer vision. $\mathrm{CV}$ is written in $\mathrm{C}++$ but it provisions different stage for the computation such as Windows, Linux, OS x, Free BSD, NetBSD and also for mobile like Android, iOS, Maemo Black berry 10. Moreover, cloud platform was implemented specially for management. The data for the presence of the car parking and number of parking availability is updated in the cloud firebase that is the real time video process though the 360-degree camera sensor and processed through the Open $\mathrm{CV}$ with python program on raspberry pi. It is able to monitor the parking area and check for the presence of cars. The cloud was connected to the mobile application. Thus, when user reserved their parking lot with specific plate number, it is automatically being updated on the cloud. There are several main components involved in the application:

1. Shows available parking lot

2. Parking lot reservation

3. User need to enter their plate number upon reservation

\section{IV.PERFORMANCE OF PROTOTYPE}

Figures 10, 11 and 12 below are the result of image / video processing recorded. For the preliminary result, the video is first recorded than processed by the Open CV software. However later, the video is live stream and the process happened at the same time.

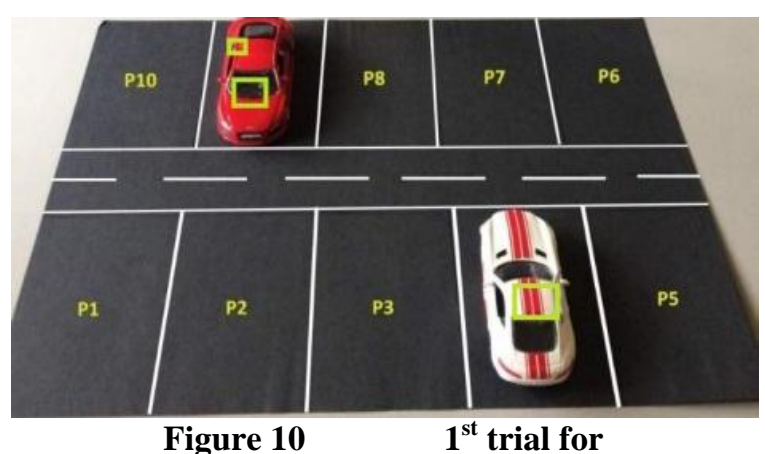

On the first trial of video processing, the detection is not very accurate, it is detected some unnecessary part of the car and background. The rectangle size, color and thickness was set inside the python program. The region of interest (RoI) was set inside the trained haar-cascade .xml file which called inside the python program. This trial was used 300 negatives background images and 150 positives subject image.

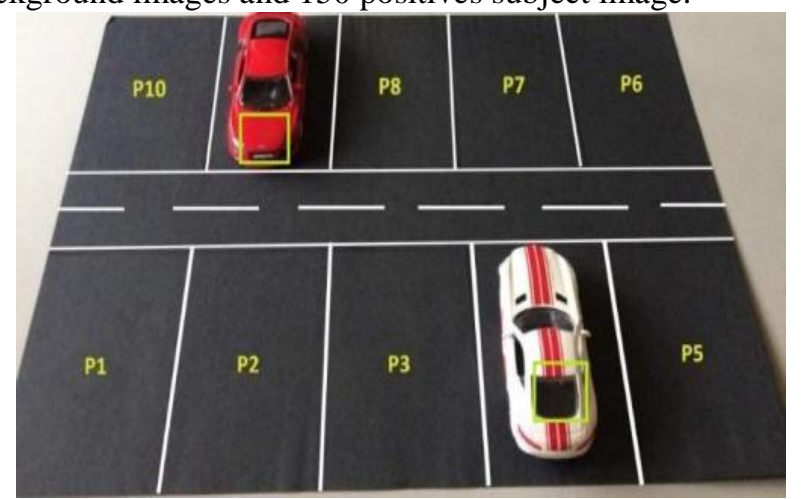

Figure $\mathbf{. 1 1 . 2 ^ { \text { nd } }}$ trial image processing for prototype
As it is seen the result for second trial, the video was recorded in light condition in sunny weather. The program is now recognized the car correctly. The accuracy of car detection is $100 \%$. However, we only need one detection per car. On this stage, the haar-cascade used are 1500 negatives background images and 750 positives subject images. It is observed that the accuracy depends of the proposed method is the number of image training for the feature detection.

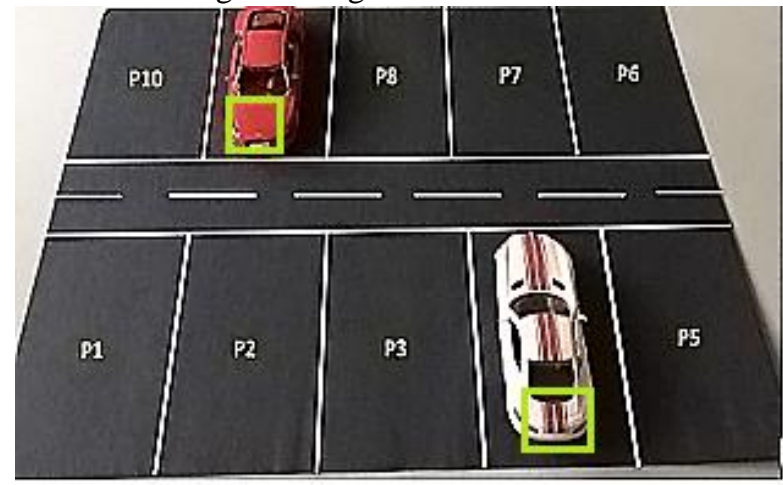

Figure.12.3 ${ }^{\text {rd }}$ trial for prototype simulation

The video was recorded in occluded weather when the light condition was quite low. But the in this situation the system can detect the car accurately until $99.49 \%$. The preliminary result is until this stage only for the prototype.

\section{EVALUATION METRIC FOR PERFORMANCE ANALYSIS}

To test the performance of proposed method, the efficiency of the system is measured with video taken at different timeintervals. The performance is calculated by comparing the results of occupancy to the ground truth value. The performance of theproposed system is measured by the using the equation (4). Ten slots per test is considered for the experiment.

Number of Total Slots $=10 *$ (Tests performed) ........ (2)

Number of Correct Slot Detections $=10 *$ (Correct Detections in the Tests performed) ............. (3) Accuracy percentage $=($ Number of correct slots detected $/$ Total slots $)$ $* 100 \ldots . .$. (4)

Table.1. Performance result of prototype

\begin{tabular}{|l|l|l|l|l|}
\hline $\begin{array}{l}\text { Car } \\
\text { appearan } \\
\text { ce }\end{array}$ & $\begin{array}{l}\text { Test } \\
\text { performe } \\
\text { d }\end{array}$ & $\begin{array}{l}\text { Correct } \\
\text { detectio } \\
\text { n }\end{array}$ & $\begin{array}{l}\text { False } \\
\text { detectio } \\
\text { n }\end{array}$ & $\begin{array}{l}\text { Accurac } \\
\mathbf{y}\end{array}$ \\
\hline Sunny & 149 & 149 & 0 & $100 \%$ \\
\hline Occluded & 199 & 198 & 1 & $99.74 \%$ \\
\hline
\end{tabular}

It can be seen from the table that the accuracy is to be $100 \%$ and $99.49 \%$ accurate during sunny and occluded weather. Low light condition has effect to decreases the efficiency and the accuracy for detections during occluded weather. It is proved that the performance is $99.74 \%$ on average. The accuracy is comparatively high among other systems detection. It is also highly depending on the camera used for the parking lot monitoring system of the proposed work.




Table.2. Comparison of Detection Rate between pieces of research works and this work based on camera and method for the prototype.

\begin{tabular}{|c|c|c|c|c|}
\hline $\begin{array}{l}\text { Author } \\
\text {-year }\end{array}$ & Title & $\begin{array}{l}\text { Proposed } \\
\text { method }\end{array}$ & $\begin{array}{l}\text { Camera/se } \\
\text { nsor }\end{array}$ & $\begin{array}{l}\text { Detecti } \\
\text { on } \\
\text { Rate }\end{array}$ \\
\hline $\begin{array}{l}\mathrm{Ng}, \\
\text { Loong, } \\
\text { Isaak, } \\
\& \\
\text { Yusof, } \\
2019\end{array}$ & $\begin{array}{l}\text { Machine } \\
\text { vision } \\
\text { based } \\
\text { smart } \\
\text { parking }\end{array}$ & $\begin{array}{l}\text { canny } \\
\text { edge } \\
\text { detection } \\
\text { technique }\end{array}$ & $\begin{array}{l}\text { 5megapixel } \\
\text { camera }\end{array}$ & $98 \%$ \\
\hline $\begin{array}{l}\text { Bao, } \\
\text { Zhan, } \\
\text { Xu, \& } \\
\mathrm{Hu}, \\
2017\end{array}$ & $\begin{array}{l}\text { A novel } \\
\text { dual } \\
\text { microwav } \\
\text { e Doppler } \\
\text { Radar } \\
\text { based } \\
\text { vehicle } \\
\text { detection } \\
\text { sensor for } \\
\text { parking } \\
\text { IoT } \\
\text { occupancy } \\
\text { detection }\end{array}$ & $\begin{array}{l}\text { Doppler } \\
\text { radar } \\
\text { sensor }\end{array}$ & $\begin{array}{l}\text { motion } \\
\text { recognition } \\
\text { method }\end{array}$ & $98 \%$ \\
\hline $\begin{array}{l}\text { This } \\
\text { researc } \\
\mathrm{h}\end{array}$ & $\begin{array}{l}\text { smart } \\
\text { parking } \\
\text { guidance } \\
\text { system } \\
\text { using } 360^{\circ} \\
\text { camera } \\
\text { and } \\
\text { haar-casca } \\
\text { de } \\
\text { classifier } \\
\text { on IoT } \\
\text { system }\end{array}$ & $\begin{array}{l}\text { 360-degre } \\
\text { e kogeto } \\
\text { lens with } 5 \\
\text { megapixel } \\
\text { camera } \\
\text { module of } \\
\text { raspberry } \\
\text { pi }\end{array}$ & $\begin{array}{l}\text { Haar-casca } \\
\text { de classifier }\end{array}$ & $99.74 \%$ \\
\hline
\end{tabular}

\section{USER ACCEPTANCE TEST WITH DEVELOPED APP AND CLOUD FIREBASE IN IoT}

The prototype provides back-end hardware and software support for users to book and access a parking spot. The system tested by providing some recorded videos that held by 360-degree camera from the prototype parking space which was arranged for 10 parking space and that was processed through the Open CV and python program which detected the presence of the car and the availability of parking data was being updated in the cloud firebase that was connected with the android app developed by android studio. Here are some of the figure showing the(UAT) User Acceptance Test.

\section{WELCOME TO \\ CAR PARKING BOOKING SYSTEM}

CarParking_Booking_System

\section{Loq In Paqe}

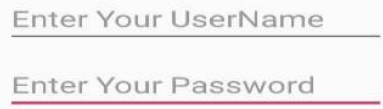

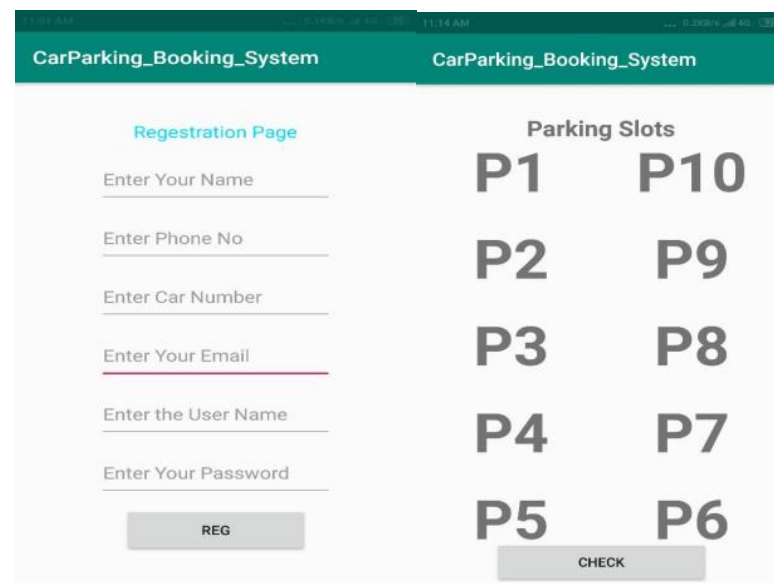

Figure15(a)Booking welcome page Figure(b) Log in or signup page Figure(c)Registration page. 
To access the parking information, users should install the app namely "Car Park Booking System" on their smart phone. Then they will be able to access the app with various activity like Figure (a). The welcome page for the interested user to access the app . To access the app, user must need to do the registration with the signup navigation bar and after doing the registration they need to login with the valid username and password that used for the registration that mentioned in figure(b), (c) and (d).

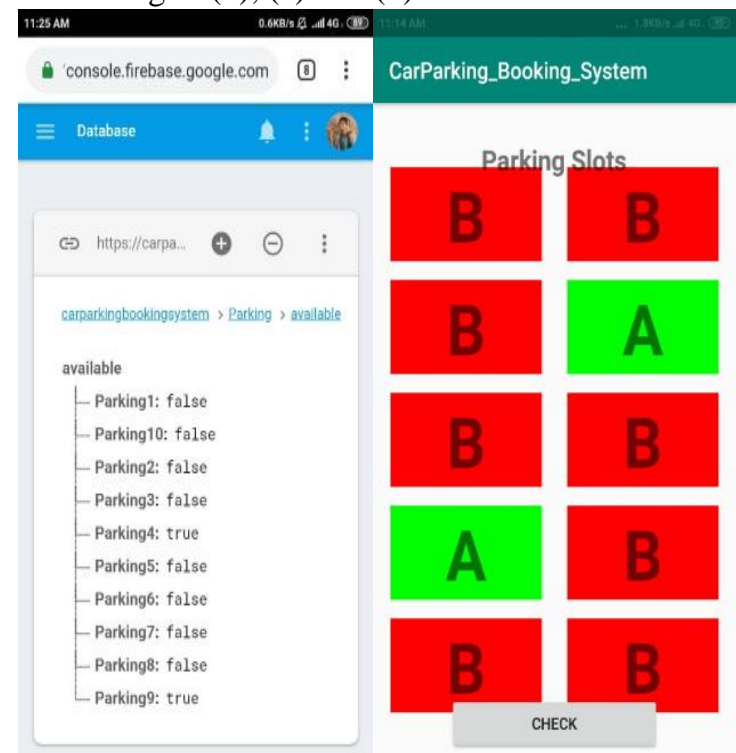

Figure(d) Log in page Figure(e)Check parking slot Figure(f) Figure (g) Parking availability information in firebase Figure (h)Access parking availability with red color.

In the figure (e) and (f) showing that after successfully login user can access the real parking information by their apps that is updating in the cloud firebase where for available number of parking space is mentioned by false condition and the presence of the car is showing with true condition. Then the data get by the app is with red color for the available parking lot and green color mentioned the booked number of lots in the figure $(\mathrm{g})$.

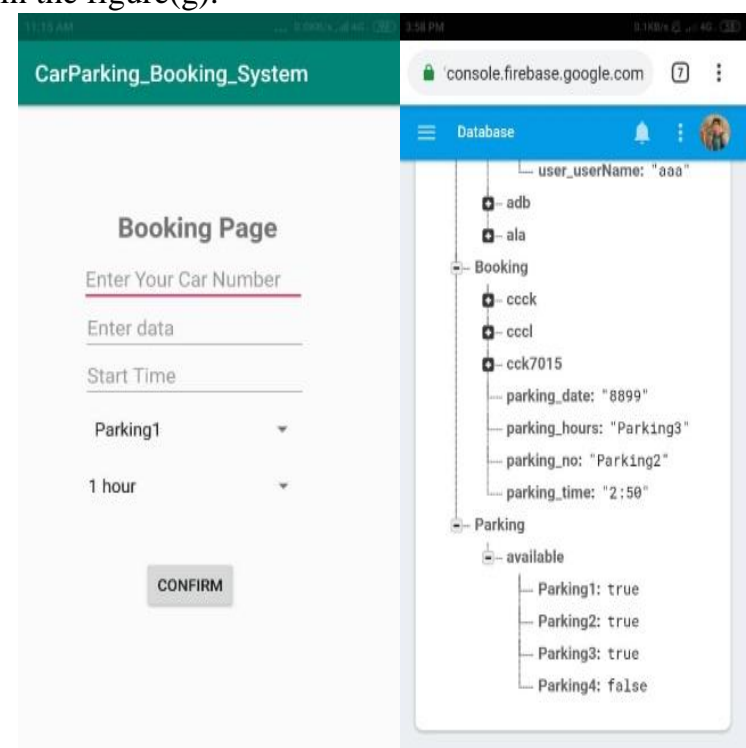

Figure. (h) Booking parking Figure (i) Update booking information in the cloud firebase and started time.
Figure(h) shows the booking process with complete the three steps that are car licence number including the date and time when want to use the park. Then that information was being updated in the cloud firebase showing in figure (i).

\section{DISCUSSION\& RESULTS}

Based on the simulation the result is satisfactory and it can come to conclude that the developed prototype is reliable and have better detection accuracy compared to others system. The UAT (User Acceptance Test) shows that $360^{\circ}$ smart parking guidance system is a research that uses IoT monitoring system for real time data and that does not involve any human involvement physically. Back end users is able to monitor real time data and interact with it from their gadgets such as smartphone through the Internet. In this research mainly the tested result is calculated based on prototype simulation. Therefore, the result tested in two weather condition like sunny and occluded where in sunny condition, the accuracy reached up to $100 \%$ but in occluded weather condition has possibility to fall the accuracy bit up to $99.49 \%$. Moreover, the accuracy depends on the number of image trailing in haar-cascade method. Because of that a large number of positive and negative images need to train where the ratio of images training is $2: 1$.

\section{VII.CONCLUSION}

Smart parking guidance systems in IoT are considered as sophisticated therefore the problem is that it's not available to the general people due to higher cost associated with the complexity related to the setting up such a system. However, due to its rising popularity in the smart parking guidance system more and more researchers are working to make this technology accessible to the population. The major objective of this research was to build an easy and efficient parking guidance system which could be used for finding and reserving the empty parking space with their mobile phone. In this attempt a prototype device that include 360-degree camera has been modified to capture image and dataset was created for training and testing purposes. Utilizing Haar-Cascade method the system was developed which is a reliable and able to detect the presence of the car and the parking space availability with $99.74 \%$ accuracy on average that is far better than other systems. By implementing this smart parking guidance system, it will lead more convenient and hassle-free lifestyle for the urban drivers as they will be able to monitor remotely and book their parking spot and this will lead to the improvement on time and fuel consumption. Moreover, communities in today's world demands more parking area that is convenient to use and less complicated. Thus, this concludes that it will lead a smarter environment and urban drivers will have a productive situation as they can monitor specific parking lot that they want to use for reserving remotely at the same saved their time and money for fuel consumption. 


\section{FUTURE WORK}

Grubbing on the knowledge and experience gained on this work, there is a huge chance of improvement in the future. At first there were some boundaries, which are needed to be stunned to make the system simply accessible. A better cloud architecture should be used because the $360^{\circ}$ camera consumes a lot of bandwidth which causes a delay during uploading and downloading process. Subsequently, replace the camera with a proper $360^{\circ}$ camera integrated with night vision abilities as to overcome low light condition. Moreover, a better method can be used to increase its accuracy because haar-cascade classifier needs a lots of positive and negative data for training and the accuracy is highly depending upon the number of trained data.

\section{ACKNOWLEDGMENT}

This work was partially supported by the Ministry of Higher Education Malaysia (Kementerian Pendidikan Tinggi) under Fundamental Research Grant Scheme number: FRGS19-068-0676.

\section{REFERENCES}

1. Aktaruzzaman, M. M., Badhan, S. M., Adnan, S., \& Alam, M. R. (2017). Application of Cloudbridge Automation using. 21-23.

2. Alsafery, W., \& Reiff-marganiec, S. (2018). Smart Car Parking System Solution for the Internet of Things in Smart Cities. 2018 1st International Conference on Computer Applications \& Information Security (ICCAIS), 1-5.

3. Bao, X., Zhan, Y., Xu, C., \& Hu, K. (2017). A novel dual microwave Doppler radar based vehicle detection sensor for parking lot occupancy detection. 14(1), 1-12. https://doi.org/10.1109/FIT.2012.24

4. Barais, O., Bourcier, J., \& Dion, C. (2016). Towards microservices architecture to transcode videos in the large at low costs.

5. Benita, M., \& Chalissery, J. (2017). Of Things-Driven Systems. (Icces), 596-599.

6. Bibi, N., Majid, M. N., Dawood, H., \& Guo, P. (2017). Automatic Parking Space Detection System. Proceedings - 2017 2nd International Conference on Multimedia and Image Processing, ICMIP 2017, 2017-Janua, 11-15. https://doi.org/10.1109/ICMIP.2017.4

7. Collage, R. V, Collage, R. V, \& Collage, R. V. (2017). IoT Based Sensor Enabled Smart Car Parking for Advanced Driver Assistance System. 2188-2193.

8. Dokur, O., Katkoori, S., \& Elmehraz, N. (2016). Embedded system design of a real-time parking guidance system. 10th Annual International Systems Conference, SysCon $2016 \quad-\quad$ Proceedings, 1-8. https://doi.org/10.1109/SYSCON.2016.7490653

9. Durnyak, B., \& Havrysh, B. (2018). Research of Image Processing Methods in Publishing Output Systems. 178-181.

10. Engineering, C. (2015). The real time monitoring of water quality in iot environment.

11. Guerrero-Ibáñez, J., Zeadally, S., \& Contreras-Castillo, J. (2018). Sensor technologies for intelligent transportation systems. Sensors (Switzerland), 18(4), 1-24. https://doi.org/10.3390/s18041212

12. Hall, J. (2010). Future Internet, Cloud Computing and VISP.

13. korea, s. (2016). predictable smart home system integrated with heterogeneous network and cloud computing. 10-13.

14. Kumar, R., Chilamkurti, N. K., \& Soh, B. (2007). A
Comparative Study of Different Sensors for Smart car park Management. 499-502. https://doi.org/10.1109/IPC.2007.29

15. Lobachev, I. (2016). Smart Sensor Network for Smart Buildings.

16. Maenhaut, P., Volckaert, B., Ongenae, V., \& Turck, F. De. (2017). Demo Abstract: RPiaaS: A Raspberry Pi Testbed for Validation of Cloud Resource Management Strategies. 946-947.

17. Ng, D., Loong, C., Isaak, S., \& Yusof, Y. (2019). Machine vision based smart parking system using Internet of Things. 17(4), 2098-2107. https://doi.org/10.12928/TELKOMNIKA.v17i4.12772

18. Ojrulwkp, Q., Zlwk, H., Dqg, V., Zlwk, L., Frqfhsw, W. K. H., Vorw, S., ... Lw, D. (2017). ,qwhooljhqw 6pduw 3dunlqj \$ojrulwkp. 1018-1022.

19. Prasse, C., \& Nettstraeter, A. (2014). How IoT will change the design and operation of logistics systems. 55-60.

20. Princy, S. E., \& Nigel, K. G. J. (2015). Implementation of Cloud Server for Real Time Data Storage using Raspberry Pi. 0-3.

21. Sardeshmukh, H., \& Ambawade, D. (2018). Internet of Things: Existing protocols and technological challenges in security. Proceedings of 2017 International Conference on Intelligent Computing and Control, I2C2 2017, 2018-Janua,

$1-7$. https://doi.org/10.1109/I2C2.2017.8321835

22. V, S. K. B. (2016). Cloud Robotics in industry using raspberry pi.

23. Viola, P., \& Jones, M. (2005). Rapid object detection using a boosted cascade of simple features. (July 2014), I-511-I-518. https://doi.org/10.1109/cvpr.2001.990517 